\title{
Enhanced Sentinel Surveillance System for COVID-19 Outbreak Prediction in a Large European Dialysis Clinics Network
}

\author{
Francesco Bellocchio ${ }^{1}$, Paola Carioni ${ }^{1}$, Caterina Lonati ${ }^{2}{ }^{(D}$, Mario Garbelli ${ }^{1}$, Francisco Martínez-Martínez ${ }^{3}$, \\ Stefano Stuard ${ }^{4}$ and Luca Neri ${ }^{1, *,+}$
}

\section{check for}

updates

Citation: Bellocchio, F.; Carioni, P.; Lonati, C.; Garbelli, M.; Martínez-Martínez, F.; Stuard, S.; Neri, L. Enhanced Sentinel Surveillance System for COVID-19 Outbreak Prediction in a Large European Dialysis Clinics Network. Int. J. Environ. Res. Public Health 2021, 18, 9739. https://doi.org/10.3390/ ijerph18189739

Academic Editors: Shang-Ming Zhou and Paul B. Tchounwou

Received: 13 July 2021

Accepted: 11 September 2021

Published: 16 September 2021

Publisher's Note: MDPI stays neutral with regard to jurisdictional claims in published maps and institutional affiliations.

Copyright: (c) 2021 by the authors. Licensee MDPI, Basel, Switzerland. This article is an open access article distributed under the terms and conditions of the Creative Commons Attribution (CC BY) license (https:/ / creativecommons.org/licenses/by/ $4.0 /)$.
1 Fresenius Medical Care Italia SpA, Palazzo Pignano, 26020 Lombardia, Italy; francesco.bellocchio@fmc-ag.com (F.B.); paola.carioni@fmc-ag.com (P.C.); mario.garbelli@fmc-ag.com (M.G.)

2 Center for Preclinical Research, Fondazione IRCCS Ca' Granda Ospedale Maggiore Policlinico, 20122 Milan, Italy; caterina.lonati@gmail.com

3 Santa Barbara Smart Health S. L., Parc Cientific Universitat id Valencia, Carrer del Catedràtic Agustín Escardino Benlloch, 9, 46980 Paterna, Spain; francisco.martinezmartinez@fmc-ag.com

4 Fresenius Medical Care Deutschland GmbH, 61352 Bad Homburg, Germany; Stefano.stuard@fmc-ag.com

* Correspondence: luca.neri@fmc-ag.com; Tel.: +39-037-327-7579 or +39-345-391-5542

† Current address: Clinical \& Data Intelligence Systems-Advanced Analytics, Fresenius Medical Care Deutschland GmbH, Via Papa Giovanni Paolo II, 41, 26020 Vaiano Cremasco, Italy.

\begin{abstract}
Accurate predictions of COVID-19 epidemic dynamics may enable timely organizational interventions in high-risk regions. We exploited the interconnection of the Fresenius Medical Care (FMC) European dialysis clinic network to develop a sentinel surveillance system for outbreak prediction. We developed an artificial intelligence-based model considering the information related to all clinics belonging to the European Nephrocare Network. The prediction tool provides risk scores of the occurrence of a COVID-19 outbreak in each dialysis center within a 2-week forecasting horizon. The model input variables include information related to the epidemic status and trends in clinical practice patterns of the target clinic, regional epidemic metrics, and the distance-weighted risk estimates of adjacent dialysis units. On the validation dates, there were 30 (5.09\%), 39 (6.52\%), and $218(36.03 \%)$ clinics with two or more patients with COVID-19 infection during the 2-week prediction window. The performance of the model was suitable in all testing windows: AUC $=0.77$, 0.80 , and 0.81 , respectively. The occurrence of new cases in a clinic propagates distance-weighted risk estimates to proximal dialysis units. Our machine learning sentinel surveillance system may allow for a prompt risk assessment and timely response to COVID-19 surges throughout networked European clinics.
\end{abstract}

Keywords: SARS-CoV-2; COVID-19; sentinel surveillance system; outbreak prediction; machine learning; artificial intelligence

\section{Introduction}

Due to its unique characteristics, the Severe Acute Respiratory Syndrome Coronavirus 2 (SARS-CoV-2) pandemic has posed unprecedented challenges to clinics providing lifesaving services to patients suffering from chronic illnesses, including chronic kidney disease (CKD). In fact, non-specific clinical manifestations of Coronavirus disease 2019 (COVID-19) [1] as well as the viral transmission from asymptomatic or pre-symptomatic individuals [2-4] make the early recognition of newly infected cases extremely difficult. Moreover, the occurrence of superspreading events (SSEV), during which few individuals are able to infect many people [5], hampers infection control measures [6,7].

Social distancing, preventive quarantine, and the isolation of infected subjects still represents the most effective means to reduce the risk of SARS-CoV-2 human-to-human transmission [8,9]. However, patients with end-stage kidney disease (ESKD) need to 
undergo in-center dialysis three times per week for $4 \mathrm{~h}$ per session, which makes physical distancing more difficult to achieve due to repeated, prolonged interactions with other patients and healthcare staff [10-13]. Unfortunately, ESKD individuals also show a higher risk of complications following SARS-CoV-2 infection due to weakened immune response [14-17] and to the occurrence of many of the risk factors commonly associated with development of severe COVID-19 [18,19], including older age and comorbidities [20,21]. Moreover, because of compromised host immunity, a vaccine may not exhibit the same efficacy on hemodialysis patients as it does in immunocompetent individuals [13].

Therefore, the reduction of the contagion risk within dialysis clinics while preserving clinical operations is a key challenge for healthcare systems during this pandemic. To help anticipate local epidemic dynamics and adjust non-pharmacological interventions to the changing background of infection risk, we sought to develop an advanced sentinel surveillance system supported by a machine learning (ML) prediction model, where the occurrence of COVID-19 cases in a clinic propagates distance-weighted risk estimates to adjacent dialysis units. The present study describes the derivation and validation of the prediction model, as well as the strategies adopted to monitor its performance throughout the pandemic period.

\section{Materials and Methods}

\subsection{Design and Setting}

All dialysis clinics belonging to the Fresenius Medical Care (FMC) European Nephrocare Network confer clinical data to a centralized data-repository, namely the European Clinical Database $\left(\mathrm{EuCliD}^{\circledR}\right.$, Fresenius Medical Care, Deutschland GmbH, Vaiano Cremasco, Italy) [22,23]. Since April 2020, all SARS-CoV-2 infections (suspected and confirmed cases as well as initial symptoms), diagnostic procedures, and clinical endpoints are reported in the treatment incident report (TIR) module in EuCLiD ${ }^{\circledR}$. We used aggregated data abstracted from the TIR, open source data describing epidemic dynamics in European countries, as well as aggregated data on biochemical assays prescriptions and results to estimate outbreak risk in dialysis clinics belonging to the FMC European Nephrocare Network.

\subsection{Outcome Variable}

The model forecasts the risk of a COVID-19 outbreak in each dialysis clinic in a 2-week horizon. Clinic outbreak is defined as the occurrence of two or more COVID-19-confirmed cases in a given clinic. Therefore, for each clinic registered in the Nephrocare network, the model estimates the probability of COVID-19 outbreak (2 or more PCR confirmed cases within a 2-week horizon) as a function of a vector of input variables. Study design is represented in Figure 1.

INDEX DATE

ASCERTAINMENT PERIOD 42 days PREDICTION PERIOD

\begin{tabular}{|c|c}
\hline \multicolumn{1}{c|}{ 42 days } & 14 days \\
\multicolumn{1}{c|}{} & previous 7d \\
\hline previous 14d & last 14d \\
\hline previous 28d & \\
\hline
\end{tabular}

Figure 1. Study design: Reference timeframe for data collection/calculation is shown.

For illustrative purposes, we established 3 risk categories: (1) low (L), when outbreak risk is less than or equal to $1.5 \%$; (2) medium (M), risk greater than $1.5 \%$ and less than or equal to $12.5 \%$; (3) high $(\mathrm{H})$, if risk is greater than $12.5 \%$. For this purpose, the action thresh- 
old defining the low risk class has been chosen to select a subpopulation of clinics where the risk of outbreak is very small so that non-pharmacological interventions to prevent the spread of COVID-19 can be temporarily and partially mitigated. In this context, a costly error would be to assign to the Low Risk class a clinic which will experience an outbreak in the following two weeks. Such threshold would be useful when a sufficiently large share of clinics (i.e., $\mathrm{P}($ Class $=\mathrm{L})$ ) could be found, so that $\mathrm{P}($ Class $=\mathrm{L} \mid$ Outbreak $=\mathrm{No})$ is high and $\mathrm{P}($ Outbreak $=$ Yes $\mid$ Class $=\mathrm{L})$ is, conversely, very small. On the other hand of the spectrum, we selected a more specific action threshold, which defines a High-Risk Class of clinics. In this risk group, additional non-pharmacological intervention should be initiated including, for example, the formal testing of temperature and thorough physical examination administered to each patient before entering the clinic or even periodical screening test (i.e., onceweekly). Since the intervention would require intensive resources, may be constraint by procurement difficulties, and would unduly overburden patients with unnecessary testing, the High Risk threshold should ideally define a group where $\mathrm{P}($ Outbreak $=$ Yes $\mid$ Class $=\mathrm{H})$ is high and both $\mathrm{P}($ Class $=\mathrm{H} \mid$ Outbreak $=\mathrm{No})$ and $\mathrm{P}($ Outbreak $=$ Yes $\mid$ Class $\neq \mathrm{H})$ are low. It is important to remark that the choice and number of the action thresholds depends on the intended use of the risk score, the set of interventions available to the organization, the price cost of each intervention, and ultimately by the value function ranking the desirability/undesirability of different health outcomes. Therefore, the thresholds presented in this paper should not be considered generalizable per se: different institutions may choose different thresholds (or no thresholds at all) depending on the availability, cost, and expected outcomes of COVID-19-related interventions (i.e., email alerts to medical directors, shipments of medical equipment such as face masks or diagnostics kits, delivery of health education modules, PCR screening, etc.).). Therefore, the problem is not diagnostic in nature, yet reduces to optimal ranking (and longitudinal stability of such ranking of risk) in order to efficiently allocate limited resources and minimize risk for the patients throughout a continuously changing epidemic landscape.

\subsection{Input Variables}

The model is computed using aggregated data provided by all the dialysis centers (min: 545; max: 611) located in one of the 23 countries of the FMC European Nephrocare Network. The final model incorporates 74 variables belonging to one of the following categories (Appendix A):

1. Open Source Data [24];

2. Epidemic status in the clinical country/region (prefix: RG): 15 parameters;

3. Aggregated Data abstracted from EuCLiD ${ }^{\circledR}$ :

a. Epidemic status in the target clinic (prefix: $\mathrm{CL}$ ): 5 variables;

b. Distance-weighted information of the adjacent clinics (prefix: CLS); 5 variables. Adjacent clinics were defined as the 3 centers with shorter distance in terms of both latitude and longitude to the target clinic. Measures of the adjacent clinics, including cases and trends, were computed as the average value weighted for the inverse of the distance to the target clinic;

c. Other parameters related to the target clinic (prefix: $\mathrm{CL}$ ): 49 parameters.

As detailed in Appendix A, each variable can be calculated/collected over different timeframes of the ascertainment period, i.e., the last 7 days (d), previous $7 \mathrm{~d}$, last $14 \mathrm{~d}$, previous $14 \mathrm{~d}$, and previous $28 \mathrm{~d}$.

\subsection{Statistical Analysis}

\subsubsection{Model Derivation}

We used XG Boost, a scalable ML system for tree boosting [25]. We used the available open source package [26] for Python, Version 3.7.4 (Python Software Foundation, Delaware, DE, United States) [27].

The first release of the model was trained using data related to 1st April 2020 (training dataset index date), while the second and the third versions were derived using data 
related to 15th July 2020 and 1st November 2020, respectively. We considered all the clinics delivering services to at least one patient on the index date as well as over the week before index date.

\subsubsection{Model Accuracy and Feature Importance}

Prediction accuracy of each release was tested every first and fifteenth day (validation dataset index dates). Therefore, development and validation datasets can include the same set of clinics/patients every two weeks.

To evaluate model performance, we measured the area under the curve (AUC) of the receiver operating characteristics (ROC) curve in the testing datasets [28] using Python, Version 3.7.4 (Python Software Foundation, Delaware, DE, United States) [27]. The AUC provides an aggregate measure of performance as the ROC curve plots the true positive rate (TPR) against the false positive rate (FPR) at all classification thresholds. Model discrimination ability over time was monitored by visual inspection of AUC trends. For illustrative purposes, we also reported the classification performance in terms of $\mathrm{P}($ Outbreak | Class) (i.e., probability of outbreak (Yes/No) given the assigned risk class $(\mathrm{L} / \mathrm{M} / \mathrm{H}))$ and $\mathrm{P}($ Class | Outbreak) (i.e., probability of the assigned risk class given the outbreak) for the two action-thresholds chosen (0.015 and 0.125). In order to calculate $\mathrm{P}($ Outbreak $\mid$ Class $)$ and $\mathrm{P}($ Class I Outbreak) we artificially treated our problem as a binary decision for each threshold. We computed average probability values across the whole study period.

Feature importance was computed using the SHapley Additive exPlanations (SHAP) method [29]. This analysis enables intuitive model explainability via an accurate and efficient estimation of the contribution to risk of each input variable.

\subsubsection{Descriptive Statistics}

For both the training and validation datasets, we analyzed the number of active clinics, frequency and incidence of a COVID-19 outbreak, the distribution of clinics in each prediction level of risk (low, medium, high), as well as the relative risk compared to clinics in low-risk groups with Python, Version 3.7.4.

\section{Results}

\subsection{Dialysis Clinic Characteristics}

Model version 1, 2, and 3 were trained using a dataset related to 1st April 2020, 15th July 2020, and 1st November 2020, respectively. On these dates, active clinics were 589, 597,603 , while $34(5.77 \%), 44(7.37 \%)$, and $233(38.64 \%)$ clinics had two or more patients with COVID-19 infection in the fortnight after the index date.

The surveillance system stratifies clinics by their risk of new local outbreak within two weeks. To facilitate the interpretation of the results, we established three risk categories: (1) Low, when outbreak risk is less than or equal to $1.5 \%$; (2) Medium, risk greater than $1.5 \%$ and less than or equal to $12.5 \%$; (3) High, if risk is greater than $12.5 \%$. Risk thresholds depend both on the incidence of pandemic and on the ability of any given clinic to implement containment measures. Figure 2 reports the share of active dialysis clinics in different risk classes at each testing date.

The actual outbreak incidence in the dialysis clinics during the validation period is reported in Figure 3. 
Temporal Trends in Risk Classes Prevalence during the study period

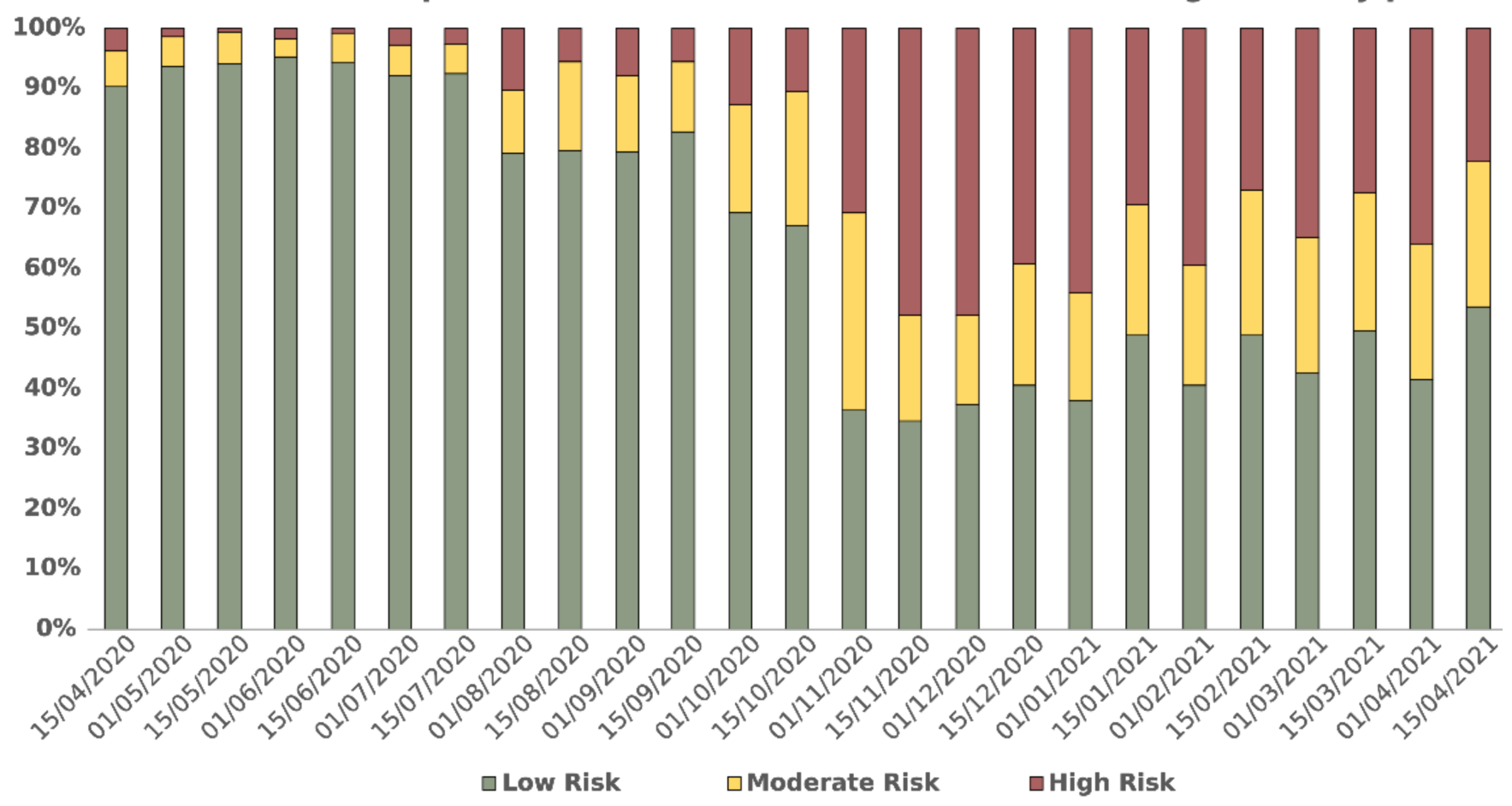

Figure 2. Number of dialysis clinics at the validation dates. Colors denote risk categories: Red, high > 12.5\%; Yellow, medium $1.5 \%<x \leq 12.5 \%$; Green, low $\leq 1.5 \%$.

\section{Temporal Trends in model discrimination accuracy and observed incidence of clinics with COVID19 outbreaks}

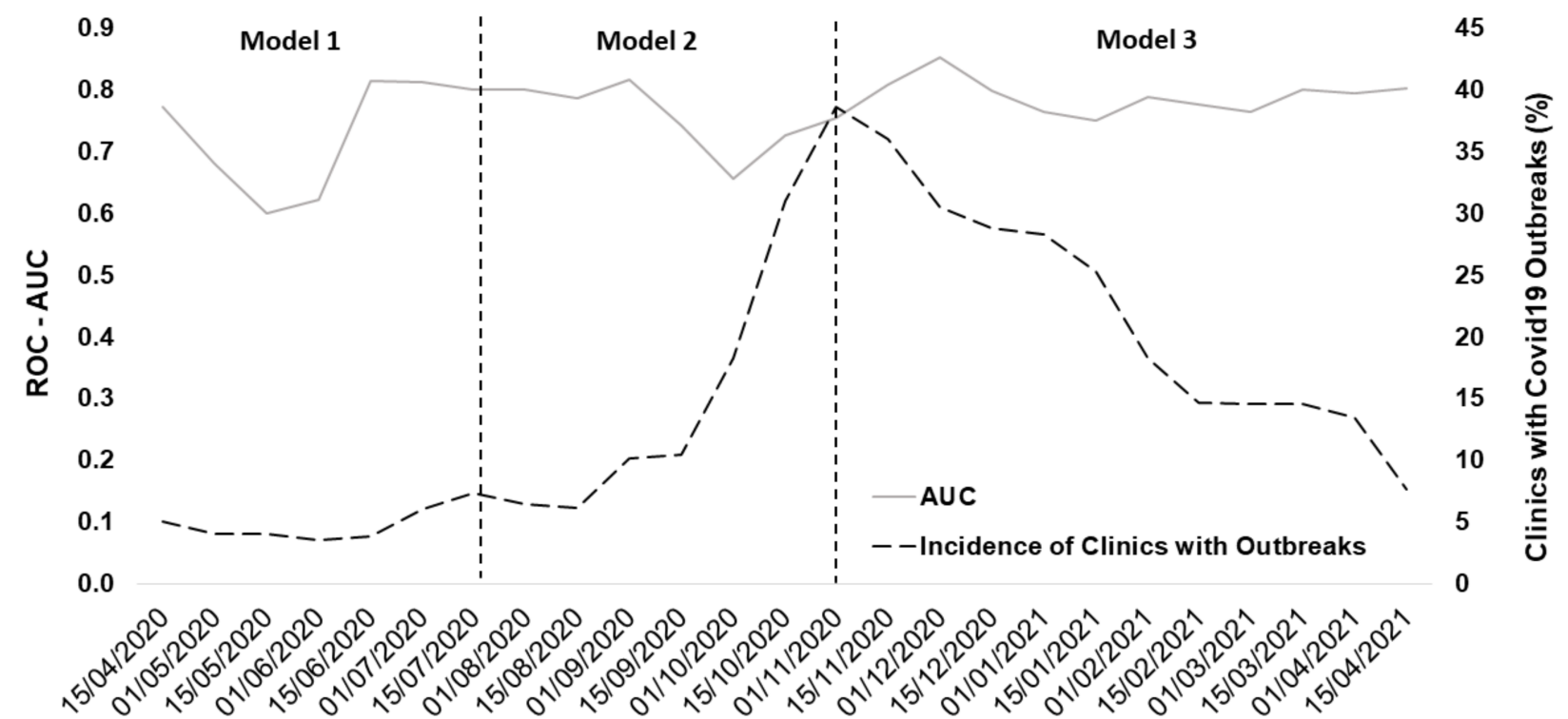

Figure 3. Model Performance and Incidence of Clinics with Outbreaks: the plot reports data related to the 1 year observation period.

\subsection{Model Performance}

All versions of the model showed a good performance over the validation period. Figure 3 shows trends in AUC values of the three model versions over a 1-year observation period. Variability in prediction accuracy decreased as retraining was applied: version 1's average AUC was 0.73 (95\% CI 0.55-0.91), AUC of version 2 was 0.75 (95\% CI 0.65-0.86), 
while version 3 had a more stable performance with an average AUC of $0.79(0.74-0.85)$.

The ROC-AUC diagram for the three model versions have been reported in Figure 4.

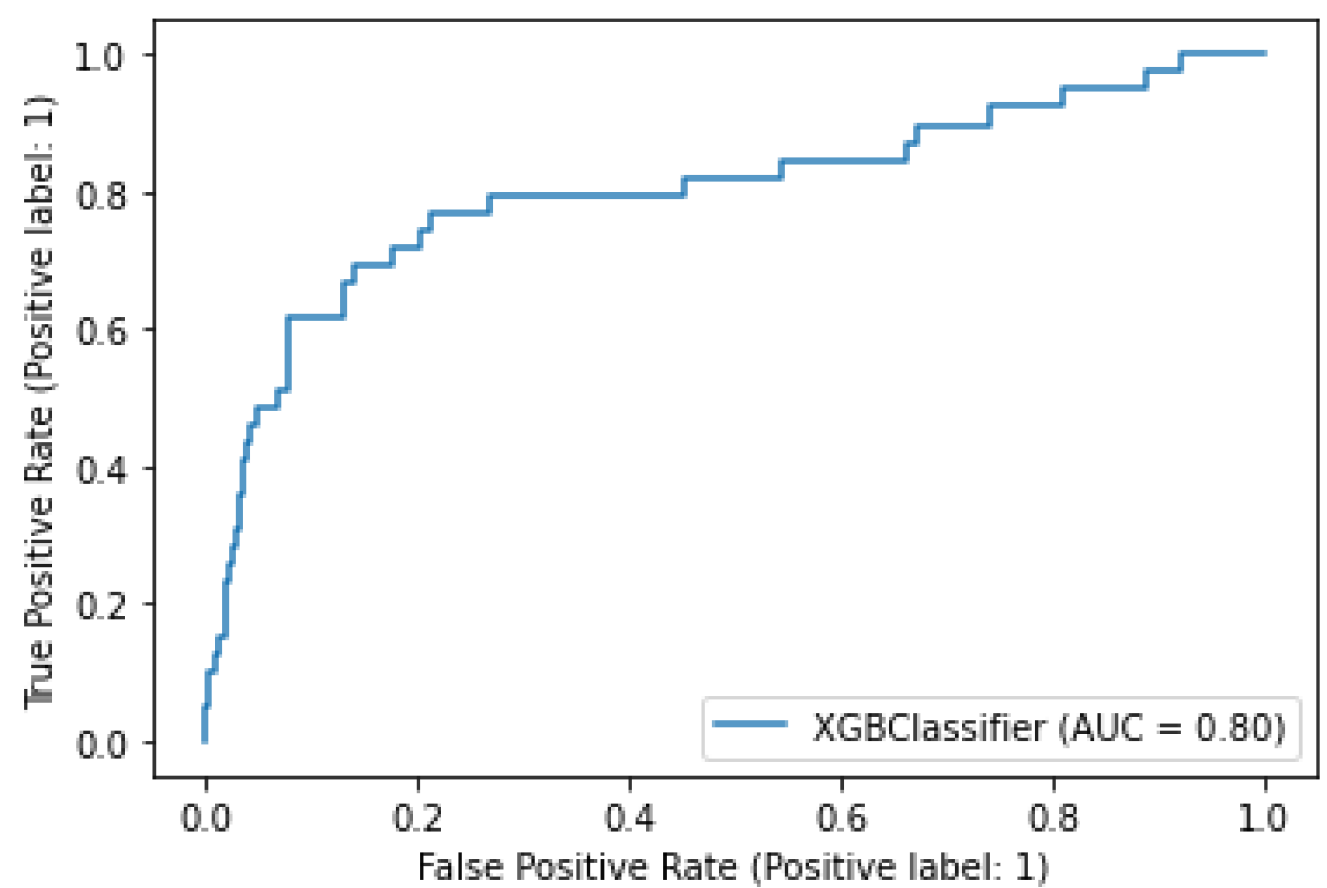

(a)

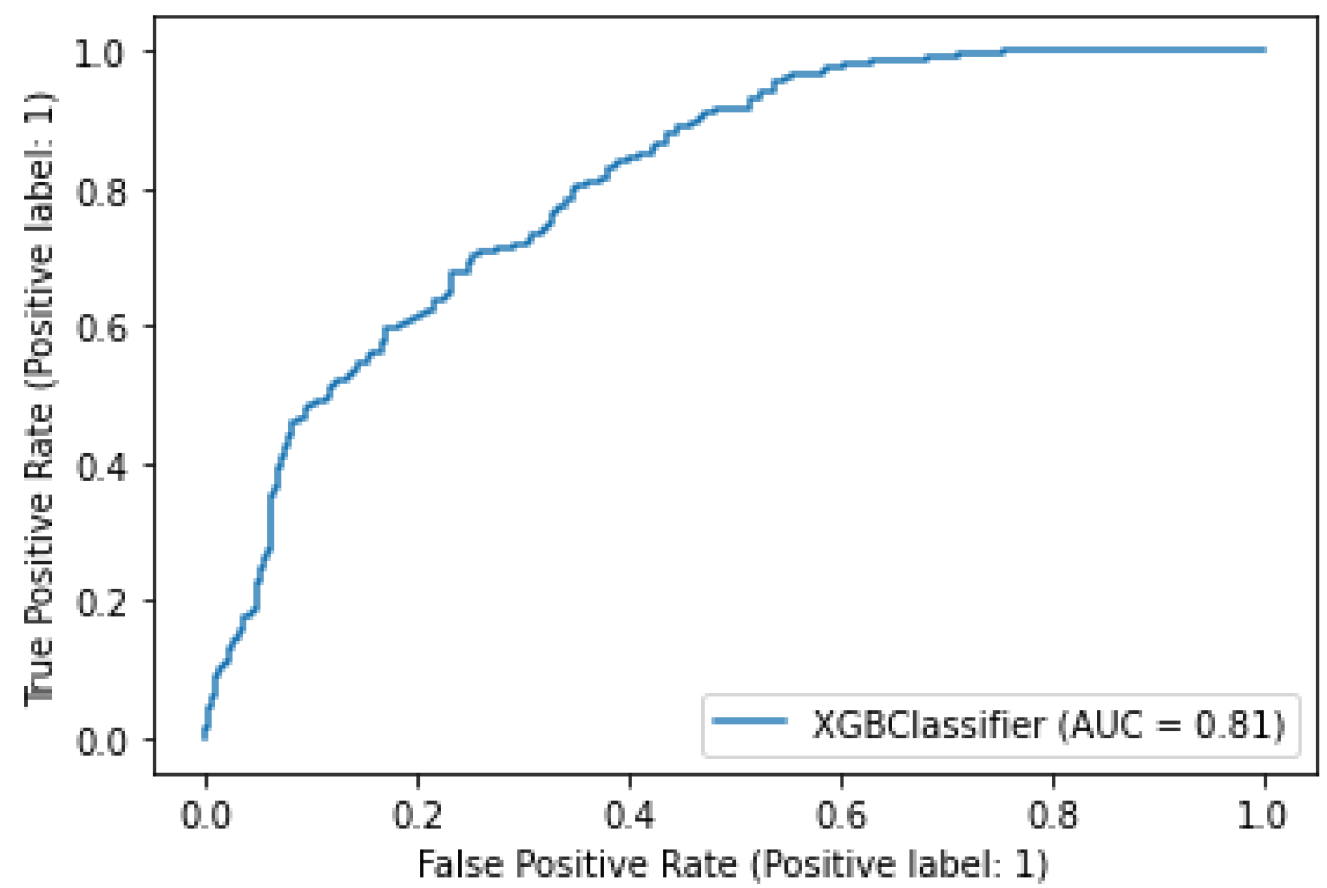

(b)

Figure 4. Cont. 


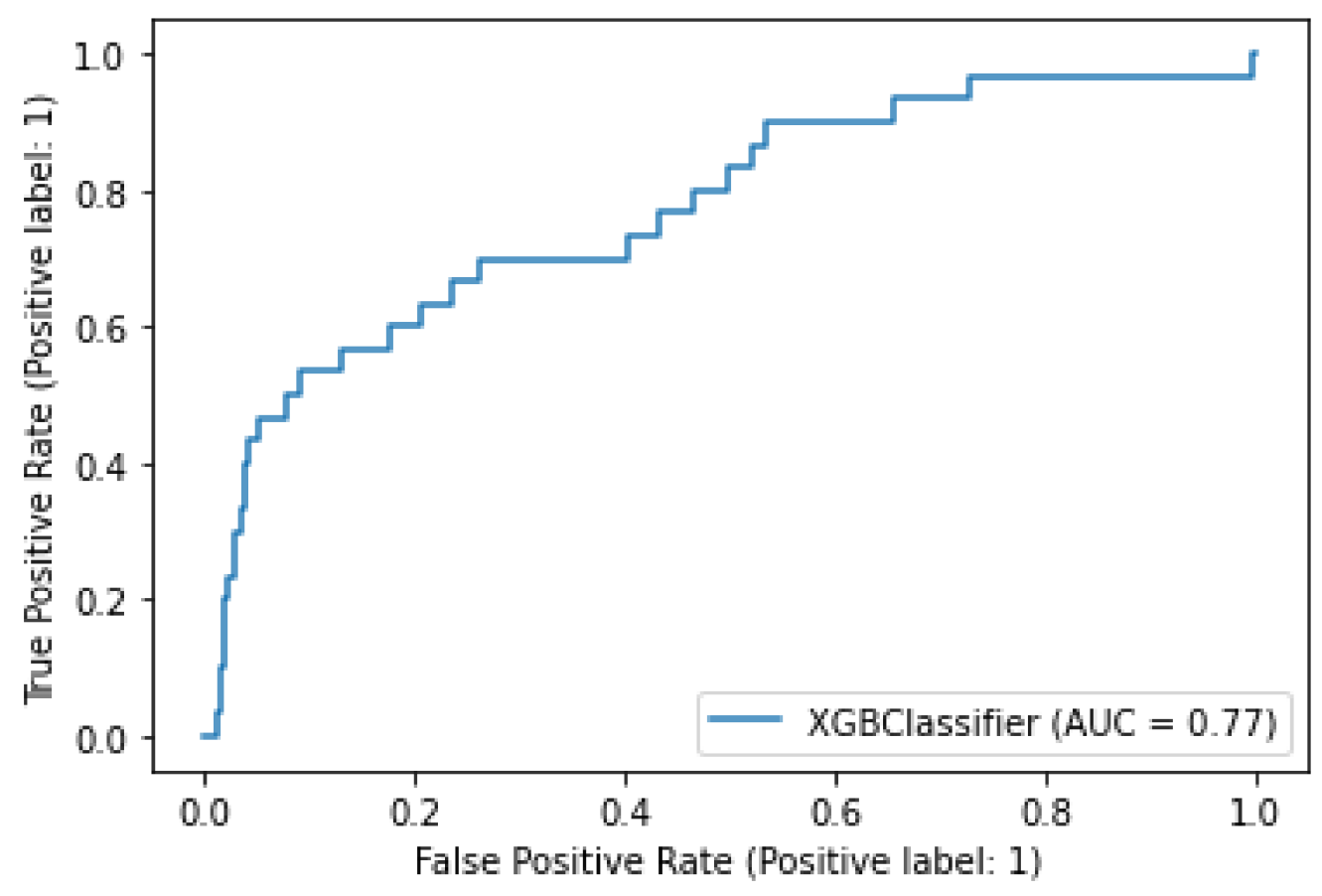

(c)

Figure 4. Panel $(\mathbf{a}-\mathbf{c})$ respectively contain the ROC-AUC plot related to Model 1, Model 2, and Model 3 evaluated on the following dates: 15 April 2020, 1 August 2020, and 15 November 2020.

In order to demonstrate the potential use of the model, we geographically mapped the risk on a few exemplary dates, i.e., the 2 August 2020, 4 October 2020, 1 November 2020, and 3 January 2020 (Figure 5). The graphical representation visually highlights clinic clusters according to the risk of a COVID-19 outbreak occurrence within 2 weeks (Figure 5, left panels, colored circles denote the low, medium, and high-risk categories). There was substantial correlation between the predicted risk (Figure 5, left panels) and the actual outcome (Figure 5, right panels) on all of the validation dates.
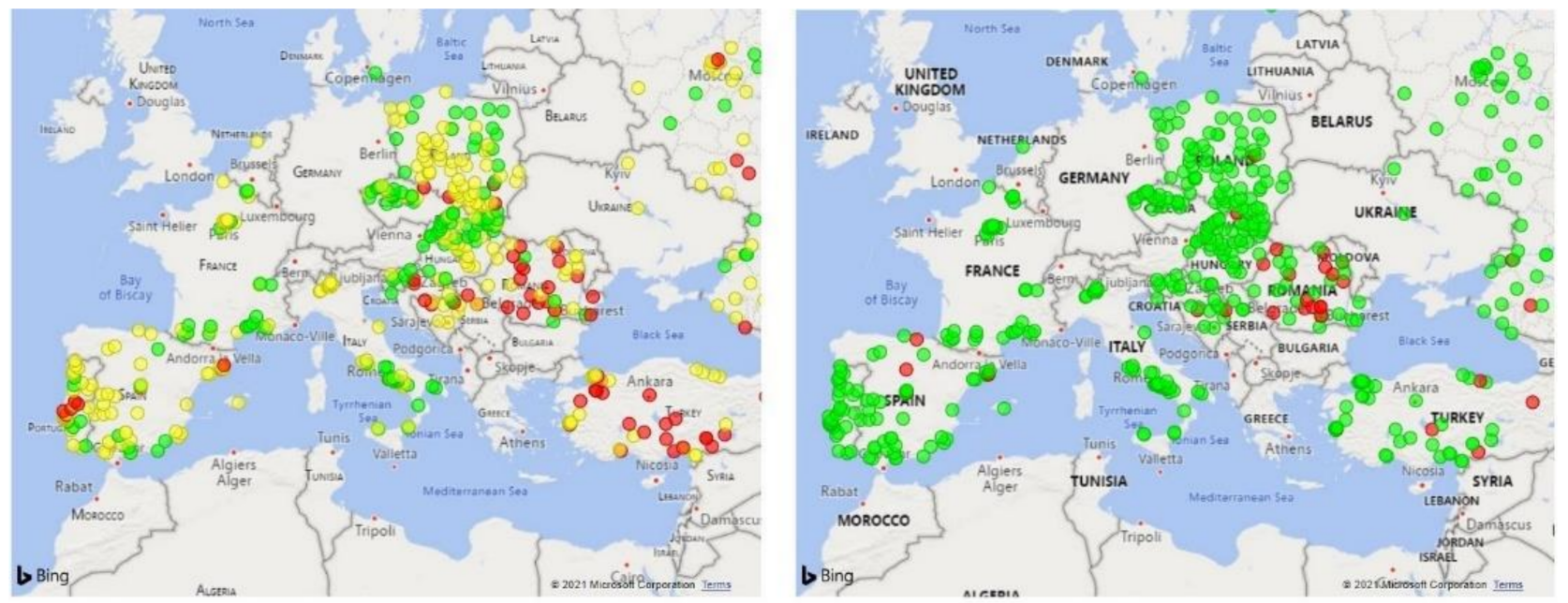

(a)

Figure 5. Cont. 

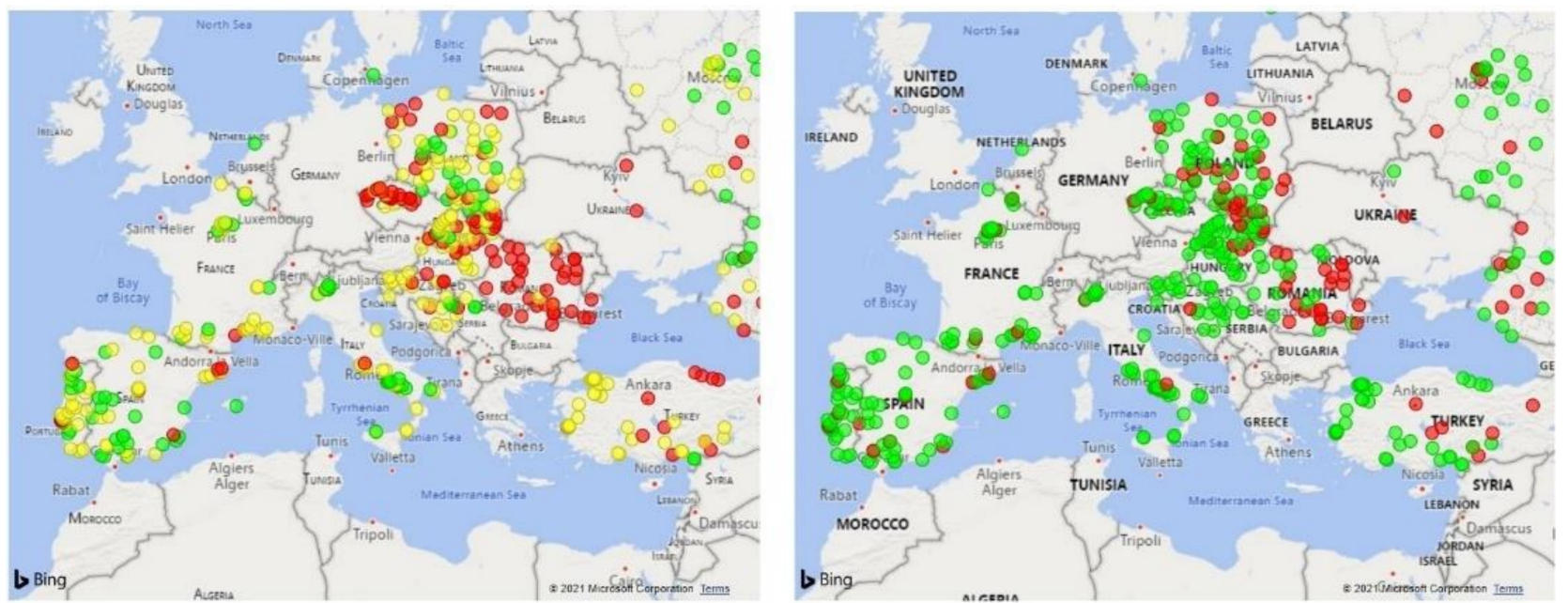

(b)
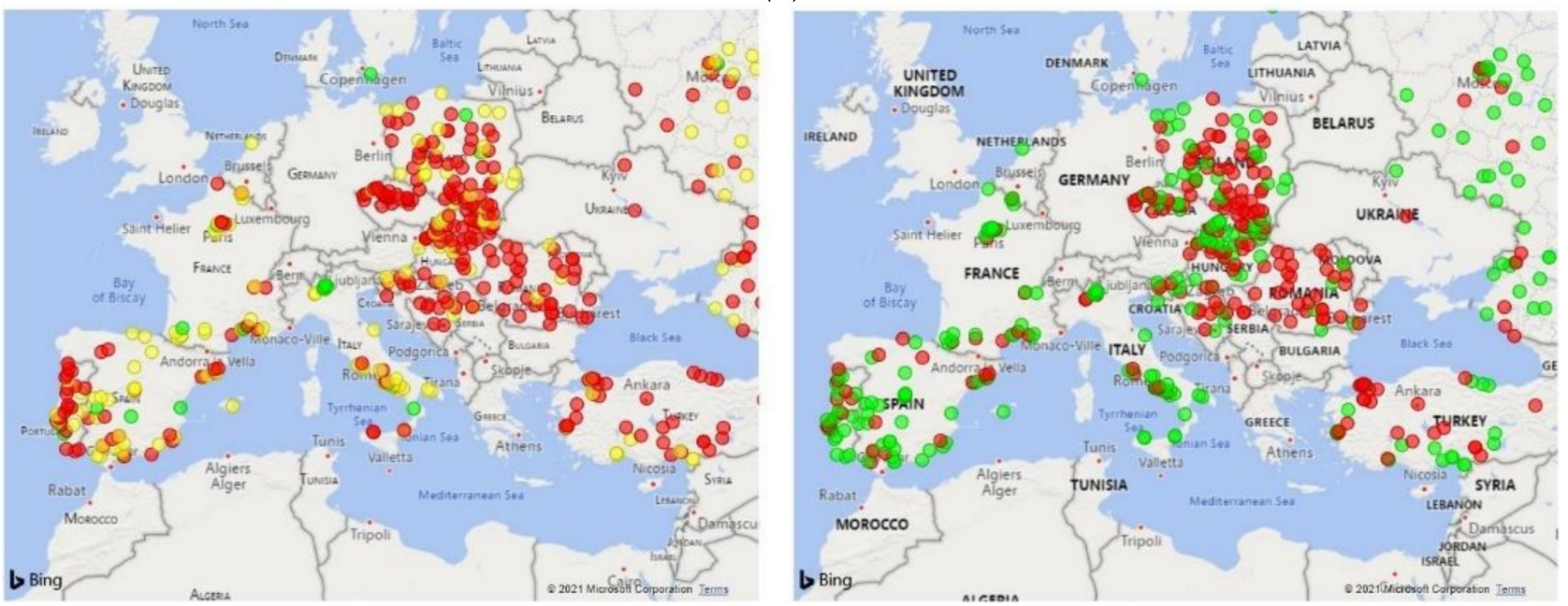

(c)
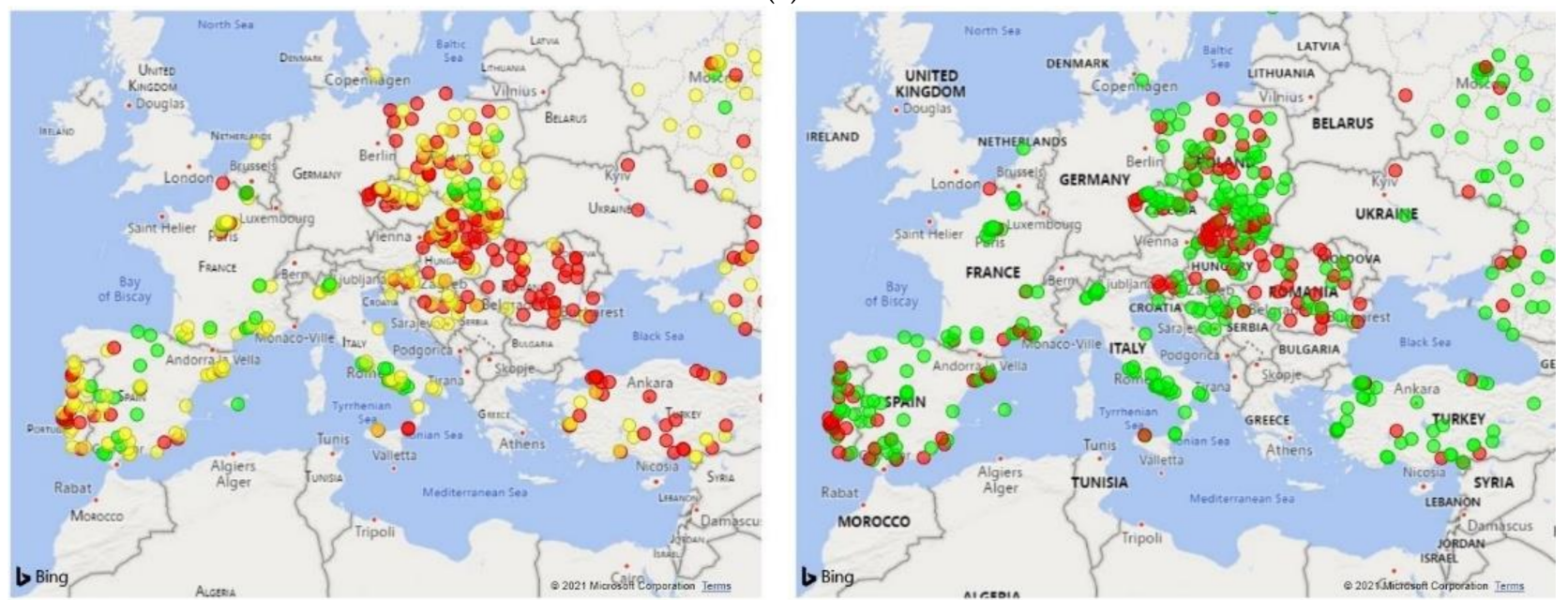

(d)

Figure 5. COVID-19 outbreak risk mapping in European clinics of the Nephrocare network. Geographical risk maps were built considering epidemic data related to the following exemplary dates: (a) 2 August 2020, (b) 4 October 2020, (c) 1 November 2020, and (d) 3 January 2020. Panels on the left show clinic clusters according to the risk of a COVID-19 outbreak occurrence within 2 weeks: Red circles: risk $>12.5 \%$; Yellow, $1.5 \%<$ risk $\leq 12.5 \%$; Green, risk $\leq 1.5 \%$. Panels on the right report the actual incidence of COVID-19 outbreaks in the forecasting period. 
Tables 1 and 2 report the classification performance in terms of $\mathrm{P}$ (Outbreak | Class) (i.e., probability of outbreak (Yes/No) given the assigned risk class $(\mathrm{L} / \mathrm{M} / \mathrm{H})$ ) and $\mathrm{P}(\mathrm{Class}$ I Outbreak) (i.e., probability of the assigned risk class given the outbreak) for the two action-thresholds chosen (0.015 and 0.125). In order to calculate P(Outbreak I Class) and $\mathrm{P}($ Class I Outbreak), we artificially treated our problem as a binary decision for each threshold. We computed average probability values across the whole study period.

Table 1. Average classification performance in terms of $\mathrm{P}(\mathrm{Outb}$ reak I Class) (i.e., probability of outbreak (Yes/No) given the assigned risk class, L) and $\mathrm{P}($ Class I Outbreak) (i.e., probability of the assigned risk class given the outbreak) at the low action-thresholds (predicted risk $=0.015$ ).

\begin{tabular}{|c|c|c|c|}
\hline \multicolumn{4}{|c|}{ Low Risk Group. P(Class $=\mathrm{L})=0.648$} \\
\hline $\mathrm{P}($ Class $=\mathrm{L}$ | Outbreak $=$ Yes $)$ & $\mathrm{P}($ Class $\neq$ L $\mid$ Outbreak $=$ Yes $)$ & $\mathrm{P}($ Class $=\mathrm{L} \mid$ Outbreak $=\mathrm{No})$ & $\mathrm{P}($ Class $\neq$ L $\mid$ Outbreak $=$ No $)$ \\
\hline 0.23 & 0.77 & 0.73 & 0.27 \\
\hline $\mathrm{P}($ Outbreak $=$ Yes $\mid$ Class $=\mathrm{L})$ & $\mathrm{P}($ Outbreak = No $\mid$ Class = L $)$ & $\mathrm{P}($ Outbreak $=$ Yes $\mid$ Class $\neq \mathrm{L})$ & $\mathrm{P}($ Outbreak $=$ No $\mid$ Class $\neq \mathrm{L})$ \\
\hline 0.06 & 0.94 & 0.37 & 0.63 \\
\hline
\end{tabular}

Table 2. Average classification performance in terms of $\mathrm{P}(\mathrm{Outbreak}$ | Class) (i.e., probability of outbreak (Yes/No) given the assigned risk class, $\mathrm{H})$ and $\mathrm{P}($ Class I Outbreak) (i.e., probability of the assigned risk class given the outbreak) at the high action-thresholds (predicted risk $=0.125$ ).

\begin{tabular}{cccc}
\hline & \multicolumn{3}{c}{ High Risk Group P(Class = H $)=\mathbf{0 . 1 9 7}$} \\
\hline $\mathrm{P}($ Class $=\mathrm{H} \mid$ Outbreak = Yes $)$ & $\mathrm{P}($ Class $\neq \mathrm{H} \mid$ Outbreak = Yes $)$ & $\mathrm{P}($ Class $=\mathrm{H} \mid$ Outbreak = No $)$ & $\mathrm{P}($ Class $\neq \mathrm{H} \mid$ Outbreak $=\mathrm{No})$ \\
0.51 & 0.49 & 0.14 & 0.86 \\
$\mathrm{P}($ Outbreak $=$ Yes $\mid$ Class $=\mathrm{H})$ & $\mathrm{P}($ Outbreak $=$ No $\mid$ Class $=\mathrm{H})$ & $\mathrm{P}($ Outbreak $=$ Yes $\mid$ Class $\neq \mathrm{H})$ & $\mathrm{P}($ Outbreak $=\mathrm{No} \mid$ Class $\neq \mathrm{H})$ \\
0.40 & 0.60 & 0.09 & 0.91 \\
\hline
\end{tabular}

Overall, the risk score was strongly associated with the likelihood of COVID-19 outbreak, as demonstrated by the relative risk of outcome occurrence in the three risk classes over the study period (Table 3 ).

Table 3. Average classification performance in terms of relative risk of COVID-19 outbreak by risk class. The relative risk is calculated as $\mathrm{RR}=\frac{P(\text { Outbreak }=\text { Yes } \mid \text { Class })}{P(\text { Outbreak }=\text { Yes } \mid \text { Class }=L)}$.

\begin{tabular}{cc}
\hline Risk Class & RR \\
\hline L & - ref \\
M & 3.45 \\
$\mathrm{H}$ & 5.95 \\
\hline
\end{tabular}

\subsection{Model Feature Importance}

Feature analysis investigated the impact of each variable on model output (Figure 6). Although there are some differences among the model versions, overall, the most important variables are related to the epidemic dynamics in the clinic in the period immediately preceding the index date for risk evaluation. Regional data on the number of COVID-19 cases and deaths were likewise ranked high. The number of COVID-19 cases in adjacent clinics resulted in the top predictor list of all three model versions. Of note, variables routinely measured in clinical practice, including changes in CRP and blood white cell count over the observation period, were also strongly associated with outbreak risk. 
Global Feature Importance

$\mathrm{CL}$ : suspected cases (last 7d)

CL: change in Mean C Reactive Protein (mg/l) (28d-14d) $\mathrm{CL}$ : change in Mean Pre/Post-HD Body Temperature $\left({ }^{\circ} \mathrm{C}\right)(28 \mathrm{~d}-14 \mathrm{~d})$

CLS: change in suspected cases (last 14d-previous 14d)

$\mathrm{CL}$ : change in number of treatments $(T x)(28 \mathrm{~d}-14 \mathrm{~d})$

$\mathrm{CL}$ : change in suspected cases (last 14d-previous $14 \mathrm{~d}$ )

RG: weekly average cumulative recovered (last 7d)

$$
\text { CL: change in Mean IDWG }(\mathrm{kg})(28 \mathrm{~d}-14 \mathrm{~d})
$$

CL: change in number of patients with labvalues (28d-14d)

CL: change in weekly dialysis frequency per clinic (28d-14d)

CL: change in Mean Leukocytes (no./ $/ \mathrm{mm}^{3}$ ) (28d-14d) CLS: suspected cases (last 7d)

$\mathrm{CL}$ : change in Mean Pre-HD DBP (mmHg) (28d-14d)

$\mathrm{CL}$ : change in Mean HD time (min) (28d-14d)

RG: weekly average cumulative cases (last $7 d$ )

RG: weekly average cumulative cases (previous 7d)

CL: change in Mean Lymphocytes (\%) (28d-14d)

RG: trend of cumulative fatalities (last $7 \mathrm{~d}$ /previous $7 \mathrm{~d}$ ) $\mathrm{CL}$ : change in weekly dialysis frequency per patient (28d-14d) CL: change in Tx with Pre/Post-HD Body Temperature (28d-14d)

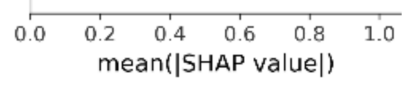

(a)

Global Feature Importance

RG: trend of cumulative fatalities (last 7d/previous 7d)

CL: change in suspected cases (last 14d-previous 14d) CLS: suspected cases (last 7d)

RG: weekly average cumulative cases (previous 7d)

$\mathrm{CL}$ : change in Mean Leukocytes (no. $\left./ \mathrm{mm}^{3}\right)$ (28d-14d)

CL: change in Mean C Reactive Protein (mg/l) (28d-14d)

CL: change in Mean IDWG $(\mathrm{kg})(28 \mathrm{~d}-14 \mathrm{~d})$

CL: change in weekly dialysis frequency per patient (28d-14d)

$\mathrm{CL}$ : change in number of labvalues (Lb) (28d-14d)

CL: change in number of treatments (Tx) (28d-14d)

CL: change in Mean Pre-HD DBP ( $\mathrm{mmHg}$ ) (28d-14d)

RG: trend of cumulative cases (last $7 \mathrm{~d} /$ previous $7 \mathrm{~d}$ )

CL: change in Lb with Albumin (28d-14d)

$\mathrm{CL}$ : change in Mean Platelets (no. $\left./ \mathrm{mm}^{3}\right)(28 \mathrm{~d}-14 \mathrm{~d})$

$\mathrm{CL}$ : change in Lb with Platelets (28d-14d)

CL: suspected cases (previous $7 \mathrm{~d}$ )

CL: change in Mean Albumin ( $/ \mathrm{d} / \mathrm{dl})(28 \mathrm{~d}-14 \mathrm{~d})$

CL: change in Tx with Pre/Post-HD Body Temperature (28d-14d)

CL: change in Lb with Ferritin (28d-14d)

CL: change in number of patients with labvalues (28d-14d)

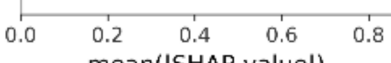

mean(|SHAP value|)

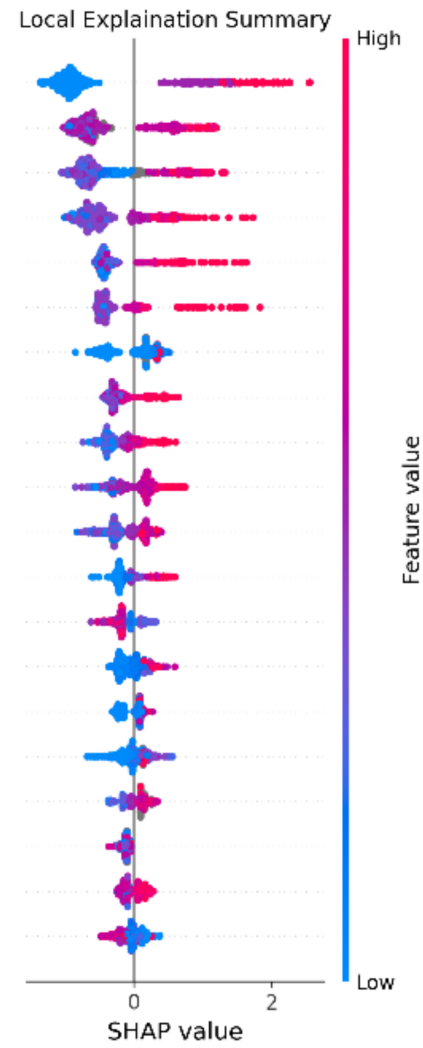

屵

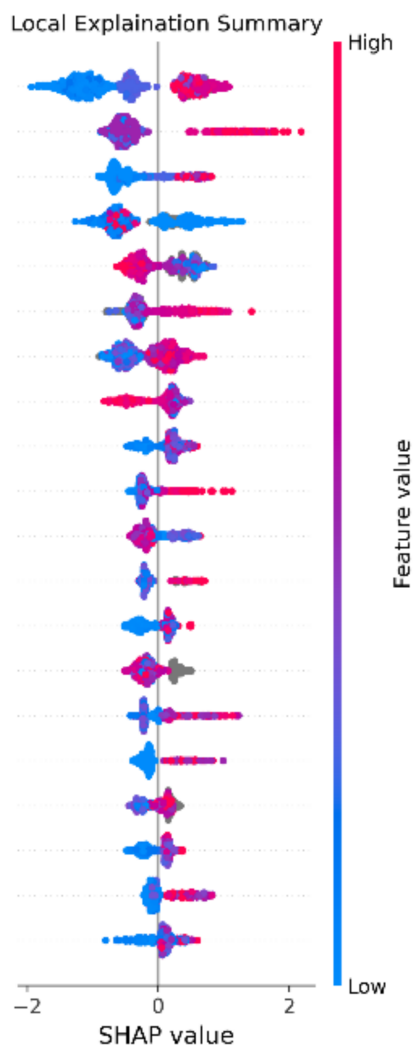

(b)

Figure 6. Cont. 

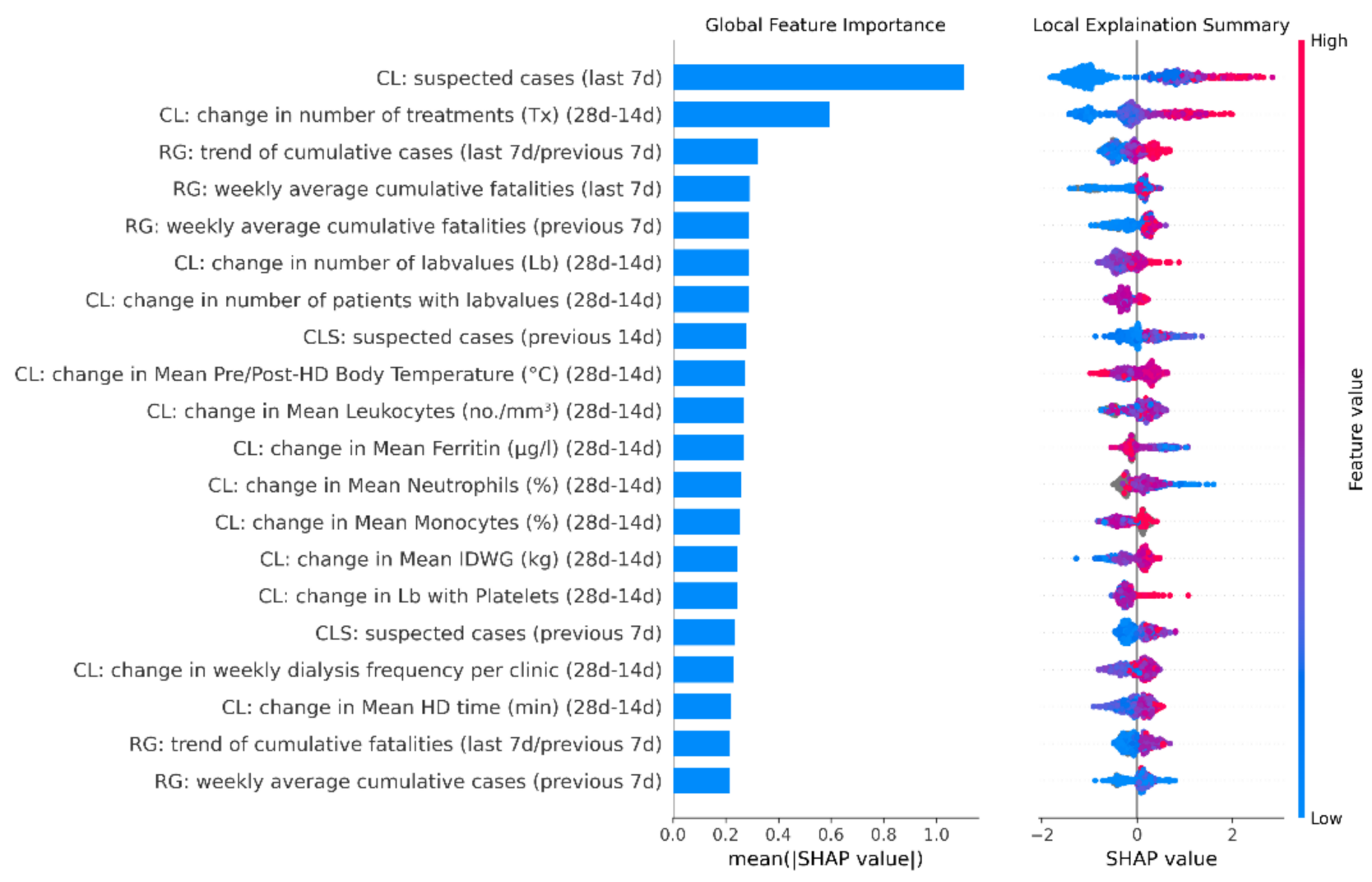

(c)

Figure 6. Panel $(\mathbf{a}-\mathbf{c})$ respectively contain the Shapley additive explanations (SHAP) related to Model 1, Model 2, and Model 3 evaluated on the following dates: 15 April 2020, 1 August 2020, and 15 November 2020. SHAP plots show relative feature importance. The blue bar represents overall SHAP values for each variable and are interpreted as relative importance of each variable to risk estimates. On the right side, SHAP values show the direction of association between predictor and risk estimates. Each dot represents one individual clinic from the test dataset. Higher values of the predictors are represented in red color; lower values of the predictors are represented in blue color. The $\mathrm{X}$ axis represents the impact of variables on risk in terms of SHAP values. Red color in correspondence with positive values suggests direct correlations between risk factors and the occurrence of COVID-19 outbreak, while red color in the region of negative SHAP values suggests inverse correlation.

\section{Discussion}

The present study describes the development and validation of a novel sentinel surveillance system allowing for the prompt risk assessment of a COVID-19 outbreak in a large European network of dialysis clinics over a 2-week forecasting horizon. The model had a stable accuracy over time and was able to consistently discriminate outbreak risk in dialysis units across all European countries at every stage of the current pandemic, i.e., during epidemic growth and decay phases. The design of our ML prediction model enables administrators and developers to quickly retrain this tool in case the visual inspection of AUC values over time suggests a trend toward a decrease in its discrimination ability.

Nosocomial transmission has greatly contributed to an increase in the global burden of COVID-19 pandemic by extremely affecting the capacity of the health system, not only to provide medical support to patients, but also to protect healthcare professionals [30,31]. Dialysis centers are particularly vulnerable to outbreak development [11,12,32] in that mitigation strategies are not entirely feasible due to the necessity of in-person encounters to provide a life-saving treatment such as hemodialysis [11]. Considering the peculiar frailty of ESKD patients, all scientific nephrology societies have provided guidance on COVID-19 transmission prevention in dialysis facilities [33-35]. In this regard, surveillance and early contagion detection are essential to reduce the risk of local outbreaks developing into epidemics. 
Clinics of the FMC European Nephrocare Network have implemented multiple nonpharmacological interventions to limit viral spreading among the CKD community, including stringent hygiene procedures, social distancing, and the identification and isolation of suspected cases. In addition, dialysis facilities have established recording pathways to report any infection event in the $\mathrm{EuCliD}^{\circledR} \mathrm{TIR}$ System. Such data are used to monitor the effectiveness of non-pharmacological intervention and to detect high-risk patients needing special attention [36-38].

One important feature of our modeling strategy entailed the combined use of open source and clinical data collected in standard clinical practice. In fact, we exploited the interconnection of the European Nephrocare clinics to augment background epidemic data with a surveillance system based on incident reports and practice pattern variation at each dialysis unit. Information about local epidemic status in a given clinic was then propagated through distance-weighting metrics to the surrounding facilities. An ML method was used to integrate all information into a summary score metric. Remarkably, variables related to the epidemic dynamics in the clinic and to the regional epidemic status, as well as to the risk proxies propagated from adjacent clinics, were all important predictors of outbreak occurrence. Such an approach is particularly relevant because it enabled us to capture local disease spread beyond the registry data compiled for the general population, which does not capture the heterogeneity of viral transmission in a setting where frequent and multiple human interactions necessarily occur. Indeed, as the basic reproduction index (R0) is a function of both the transmissibility of a disease and the contact patterns that underlie transmission [39], the regional/provincial R0 cannot be translated in dialysis facilities in that ESKD patients' biological and socio-behavioral factors significantly differ from those of the general population [40]. The occurrence of SSEVs further complicates the picture, making generalizations of regional epidemic trends that are not entirely appropriate for the reliable prediction of viral spreading in healthcare settings [41,42].

The interconnection of the FMC network allows for the collection and subsequent central integration of a bulk of information provided by facilities distributed throughout European countries. This particular setting offers the advantage to perform the real-time monitoring of sentinel sensors that are likely to provide timely and accurate indications of epidemic activity [43], while considering the heterogeneity underlying transmission dynamics. Sentinel surveillance in outpatient settings was previously shown to provide a robust approach to oversee SARS-CoV-2 spreading [44]. In general, the monitoring of community transmission in nodes distributed across different regions was reported to ensure efficient disease detection in networked populations [45]. It is important to highlight that the analytic strategy adopted in this study is general and can be applied to any epidemic communicable disease, as all naturally occurring, clustering units where social promiscuity, density, and duration of interactions are substantially different compared to the general population. Henceforth, this method may be applied to social contexts with a high risk of outbreak generation, including schools, hospitals, and workplaces from which the provided infection data are promptly captured and conferred to a central database, even in aggregated form. Monitoring of the pandemic situation within the network allows for the timely implementation of infection control procedures in the adjacent networked unit and efficiently anticipates resource needs.

Finally, variable importance analysis has indicated that trends in clinical practice patterns are among the top predictors. This observation indicates that the tracking of physicians' prescription behavior can provide valuable information to assess epidemic dynamics also during explosive growth, when surveillance and laboratory resources are limited and COVID-19 cases may be recorded with some delay due to the emergency situation [46].

\section{Conclusions}

Our sentinel surveillance system allows for a prompt risk assessment and timely response to the challenges posed by the COVID-19 epidemic throughout FMC European 
dialysis clinics. This tool can have significant implications for public health practice in that it represents a robust strategy to assess the level of community transmission of COVID-19 and to guide the selection and implementation of mitigation measures. The same framework can be applied in other networked settings, such as healthcare facilities or schools to improve early detection and forecasting of SARS-CoV-2 transmission. Finally, the implementation of our surveillance system can guide preparedness efforts for future pandemics.

Author Contributions: Conceptualization: F.B. and L.N.; data curation: M.G. and F.M.-M.; formal analysis: P.C., M.G. and F.M.-M.; supervision: S.S.; validation: F.B., L.N. and S.S.; writing-original draft: P.C. and C.L.; writing—review and editing: F.B., P.C., C.L. and L.N. All authors have read and agreed to the published version of the manuscript.

Funding: This research was funded by Fresenius Medical Care Deutschland GmbH.

Institutional Review Board Statement: The study was conducted according to the guidelines of the Declaration of Helsinki. IRB approval was not necessary because all input data for modeling were aggregated statistics concerning COVID-19 infection distribution and practice patterns across dialysis centers (i.e., cumulative number of infections in countries, number of prescribed laboratory tests in dialysis centers, number of new cases in dialysis centers). No patients' personal information has been used for the present study.

Informed Consent Statement: No patients' personal information has been used for the present study since all input data for modeling were aggregated statistics concerning COVID-19 infection distribution and practice patterns across dialysis centers (i.e., cumulative number of infections in countries, number of prescribed laboratory tests in dialysis centers, number of new cases in dialysis centers).

Data Availability Statement: Open source datasets adopted for the study have been referenced throughout the manuscript. Restrictions apply to the availability of these data. Data was obtained from Fresenius Medical Care and may be available for specific, well-motivated requests, from the corresponding author with the permission of Fresenius Medical Care.

Conflicts of Interest: C.L. received consultancy fees from Fresenius Medical Care Deutschland GmbH. All remaining authors are full time employees of Fresenius Medical Care Deutschland GmbH.

\section{Appendix A}

Table A1. Variables included in the model.

\begin{tabular}{|c|c|c|}
\hline Category & Variable & Reference Time \\
\hline \multicolumn{3}{|c|}{ Epidemic Status in the Country/Region (prefix: RG) } \\
\hline & cumulative cases & previous 7 days and last 7 days \\
\hline & number of hospitalized & previous 7 days and last 7 days \\
\hline & number of ICU patients & previous 7 days and last 7 days \\
\hline & cumulative fatalities & previous 7 days and last 7 days \\
\hline & cumulative recovered & previous 7 days and last 7 days \\
\hline & trend of cumulative cases & last 7 days/previous 7 days \\
\hline Category & Variable & Reference Time \\
\hline \multirow{5}{*}{\multicolumn{3}{|c|}{$\begin{array}{l}\text { trend of cumulative fat } \\
\text { epidemic status in the clinic (prefix: } C L \text { ) }\end{array}$}} \\
\hline & & \\
\hline & & \\
\hline & & \\
\hline & & \\
\hline & number of suspected COVID-19 cases & $\begin{array}{c}\text { previous } 14 \text { days, previous } 7 \text { days, and } \\
\text { last } 7 \text { days }\end{array}$ \\
\hline & change in suspected cases & last 7 days-previous 7 days \\
\hline & change in suspected cases & last 14 days-previous 14 days \\
\hline
\end{tabular}


Table A1. Cont.

\begin{tabular}{|c|c|c|}
\hline Category & Variable & Reference Time \\
\hline \multicolumn{3}{|c|}{ distance-weighted information of the adjacent clinics (prefix: CL) } \\
\hline & number of COVID-19 suspected cases & previous $14 \mathrm{~d}$, previous 7 days, and last \\
\hline & in the closest clinics & 7 days \\
\hline & $\begin{array}{l}\text { change in COVID-19 suspected cases in } \\
\text { the closest clinics }\end{array}$ & last 7 days-previous 7 days \\
\hline & $\begin{array}{c}\text { change in COVID-19 suspected cases in } \\
\text { the closest clinics }\end{array}$ & last 14 days-previous 14 days \\
\hline \multicolumn{3}{|c|}{ other parameters related to the clinic (prefix: CL) } \\
\hline & $\begin{array}{c}\text { change in the number of treated } \\
\text { patients }\end{array}$ & last 28 days-last 14 days \\
\hline & change in the number of treatments & last 28 days-last 14 days \\
\hline & $\begin{array}{c}\text { change in the weekly dialysis frequency } \\
\text { per clinic }\end{array}$ & last 28 days-last 14 days \\
\hline & $\begin{array}{c}\text { change in the weekly dialysis frequency } \\
\text { per patient }\end{array}$ & last 28 days-last 14 days \\
\hline & change in the number of treatments & last 28 days-last 14 days \\
\hline & $\begin{array}{l}\text { with pre/post-B I } \\
\text { change in the number of treatments }\end{array}$ & \\
\hline & with pre $/$ post-BT $>37^{\circ} \mathrm{C}$ & last 28 days-last 14 days \\
\hline & $\begin{array}{l}\text { change in the percentage of treatments } \\
\text { with pre/post-BT }>37^{\circ} \mathrm{C}\end{array}$ & last 28 days-last 14 days \\
\hline & $\begin{array}{c}\text { change in the mean value of } \\
\text { pre/post-dialysis BT }\end{array}$ & last 28 days-last 14 days \\
\hline & change in the number of treatments & last 28 days-last 14 days \\
\hline & with pre-dyalisis diastolic BP & 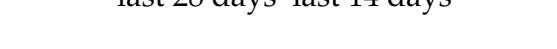 \\
\hline & $\begin{array}{l}\text { change in the mean value of } \\
\text { pre-dialysis diastolic BP }\end{array}$ & last 28 days-last 14 days \\
\hline & $\begin{array}{l}\text { change in the number of treatments } \\
\text { with dialysis time }\end{array}$ & last 28 days-last 14 days \\
\hline & $\begin{array}{c}\text { change in the mean value of dialysis } \\
\text { time }\end{array}$ & last 28 days-last 14 days \\
\hline & change in the number of treatments & \\
\hline & with IDWG & last 28 days-last 14 days \\
\hline & change in the mean value of IDWG & last 28 days-last 14 days \\
\hline & $\begin{array}{c}\text { change in the number of treatments } \\
\text { with } \mathrm{O} 2 \text { sat }\end{array}$ & last 28 days-last 14 days \\
\hline & change in the mean value of $\mathrm{O} 2$ sat & last 28 days-last 14 days \\
\hline & $\begin{array}{l}\text { change in the number of patients with } \\
\text { lab tests }\end{array}$ & last 28 days-last 14 days \\
\hline & change in the number of lab tests & last 28 days-last 14 days \\
\hline & change in the number of lab tests with & last 28 days-last 14 days \\
\hline & Albumin & \\
\hline & change in the mean value of Albumin & last 28 days-last 14 days \\
\hline & $\begin{array}{c}\text { change in the number of lab tests with } \\
\text { lymphocytes }\end{array}$ & last 28 days-last 14 days \\
\hline & $\begin{array}{c}\text { change in the mean value of } \\
\text { lymphocytes }\end{array}$ & last 28 days-last 14 days \\
\hline & change in the number of lab tests with & last 28 days-last 14 days \\
\hline & change in the mean value of monocytes & last 28 days-last 14 days \\
\hline & $\begin{array}{c}\text { change in the number of lab tests with } \\
\text { neutrophils }\end{array}$ & last 28 days-last 14 days \\
\hline & $\begin{array}{c}\text { change in the mean value of } \\
\text { neutrophils }\end{array}$ & last 28 days-last 14 days \\
\hline & change in the number of lab tests with & last 28 days-last 14 days \\
\hline & change in the mean value of platelets & last 28 days-last 14 days \\
\hline & $\begin{array}{l}\text { change in the number of lab tests with } \\
\text { PDW }\end{array}$ & last 28 days-last 14 days \\
\hline
\end{tabular}


Table A1. Cont.

\begin{tabular}{|c|c|c|}
\hline Category & Variable & Reference Time \\
\hline & change in the mean value of PDW & last 28 days-last 14 days \\
\hline & $\begin{array}{c}\text { change in the number of lab tests with } \\
\text { leukocytes }\end{array}$ & last 28 days-last 14 days \\
\hline & change in the mean value of leukocytes & last 28 days-last 14 days \\
\hline & $\begin{array}{c}\text { change in the number of lab tests with } \\
\text { D-dimer }\end{array}$ & last 28 days-last 14 days \\
\hline & change in the mean value of D-dimer & last 28 days-last 14 days \\
\hline & $\begin{array}{c}\text { change in the number of lab tests with } \\
\text { CRP }\end{array}$ & last 28 days-last 14 days \\
\hline & change in the mean value of CRP & last 28 days-last 14 days \\
\hline & $\begin{array}{c}\text { change in the number of lab tests with } \\
\text { IL-6 }\end{array}$ & last 28 days-last 14 days \\
\hline & change in the mean value of IL-6 & last 28 days-last 14 days \\
\hline & $\begin{array}{l}\text { change in the number of lab tests with } \\
\text { ANP }\end{array}$ & last 28 days-last 14 days \\
\hline & change in the mean value of ANP & last 28 days-last 14 days \\
\hline & $\begin{array}{c}\text { change in the number of lab tests with } \\
\text { BNP }\end{array}$ & last 28 days-last 14 days \\
\hline & change in the mean value of BNP & last 28 days-last 14 days \\
\hline & $\begin{array}{c}\text { change in the number of lab tests with } \\
\text { Ferritin }\end{array}$ & last 28 days-last 14 days \\
\hline & change in the mean value of Ferritin & last 28 days-last 14 days \\
\hline & $\begin{array}{c}\text { Number of patients with at least one } \\
\text { hospitalization }\end{array}$ & last 14 days \\
\hline & Number of hospitalizations & last 14 days \\
\hline
\end{tabular}

\section{References}

1. Li, J.; Huang, D.Q.; Zou, B.; Yang, H.; Hui, W.Z.; Rui, F.; Yee, N.T.S.; Liu, C.; Nerurkar, S.N.; Kai, J.C.Y.; et al. Epidemiology of COVID-19: A systematic review and meta-analysis of clinical characteristics, risk factors, and outcomes. J. Med. Virol. 2021, 93, 1449-1458. [CrossRef]

2. Muller, C.P. Do asymptomatic carriers of SARS-COV-2 transmit the virus? Lancet Reg. Health 2021, 4, 100082. [CrossRef]

3. He, X.; Lau, E.H.Y.; Wu, P.; Deng, X.; Wang, J.; Hao, X.; Lau, Y.C.; Wong, J.Y.; Guan, Y.; Tan, X.; et al. Temporal dynamics in viral shedding and transmissibility of COVID-19. Nat. Med. 2020, 26, 672-675. [CrossRef] [PubMed]

4. Byambasuren, O.; Cardona, M.; Bell, K.; Clark, J.; McLaws, M.-L.; Glasziou, P. Estimating the extent of asymptomatic COVID-19 and its potential for community transmission: Systematic review and meta-analysis. JAMMI Off. J. Assoc. Med. Microbiol. Infect. Dis. Can. 2020, 5, 223-234. [CrossRef]

5. Galvani, A.P.; May, R.M. Epidemiology: Dimensions of superspreading. Nature 2005, 438, 293-295. [CrossRef] [PubMed]

6. Lemieux, J.; Siddle, K.J.; Shaw, B.M.; Loreth, C.; Schaffner, S.; Gladden-Young, A.; Adams, G.; Fink, T.; Tomkins-Tinch, C.H.; Krasilnikova, L.A.; et al. Phylogenetic analysis of SARS-CoV-2 in the Boston area highlights the role of recurrent importation and superspreading events. medRxiv 2020, PMC7457619. [CrossRef]

7. Lewis, D. Superspreading drives the COVID pandemic-and could help to tame it. Nature 2021, 590, 544-546. [CrossRef]

8. Chu, D.K.; Akl, E.A.; Duda, S.; Solo, K.; Yaacoub, S.; Schünemann, H.J.; El-harakeh, A.; Bognanni, A.; Lotfi, T.; Loeb, M.; et al. Physical distancing, face masks, and eye protection to prevent person-to-person transmission of SARS-CoV-2 and COVID-19: A systematic review and meta-analysis. Lancet 2020, 395, 1973-1987. [CrossRef]

9. Regmi, K.; Lwin, C.M. Impact of non-pharmaceutical interventions for reducing transmission of COVID-19: A systematic review and meta-analysis protocol. BMJ Open 2020, 10, e041383. [CrossRef]

10. Apata, I.W.; Cobb, J.; Navarrete, J.; Burkart, J.; Plantinga, L.; Lea, J.P. COVID-19 infection control measures and outcomes in urban dialysis centers in predominantly African American communities. BMC Nephrol. 2021, 22, 81. [CrossRef]

11. Weiner, D.E.; Watnick, S.G. Hemodialysis and COVID-19: An Achilles' Heel in the Pandemic Health Care Response in the United States. Kidney Med. 2020, 2, 227-230. [CrossRef]

12. Meijers, B.; Messa, P.; Ronco, C. Safeguarding the Maintenance Hemodialysis Patient Population during the Coronavirus Disease 19 Pandemic. Blood Purif. 2020, 49, 259-264. [CrossRef]

13. Li, S.Y.; Tang, Y.S.; Chan, Y.J.; Tarng, D.C. Impact of the COVID-19 pandemic on the management of patients with end-stage renal disease. J. Chin. Med. Assoc. 2020, 83, 628-633. [CrossRef]

14. Lamarche, C.; Iliuta, I.A.; Kitzler, T. Infectious Disease Risk in Dialysis Patients: A Transdisciplinary Approach. Can. J. Kidney Health Dis. 2019, 6, 2054358119839080. [CrossRef] [PubMed] 
15. Clarke, C.L.; Prendecki, M.; Dhutia, A.; Gan, J.; Edwards, C.; Prout, V.; Lightstone, L.; Parker, E.; Marchesin, F.; Griffith, M.; et al. Longevity of SARS-CoV-2 immune responses in hemodialysis patients and protection against reinfection. Kidney Int. 2021, 99, 1470-1477. [CrossRef]

16. Lisowska, K.A.; Pindel, M.; Pietruczuk, K.; Kuźmiuk-Glembin, I.; Storoniak, H.; Dębska-Ślizień, A.; Witkowski, J.M. The influence of a single hemodialysis procedure on human T lymphocytes. Sci. Rep. 2019, 9, 5041. [CrossRef] [PubMed]

17. Betjes, M.G.H. Immune cell dysfunction and inflammation in end-stage renal disease. Nat. Rev. Nephrol. 2013, 9, 255-265. [CrossRef] [PubMed]

18. Williamson, E.J.; Walker, A.J.; Bhaskaran, K.; Bacon, S.; Bates, C.; Morton, C.E.; Curtis, H.J.; Mehrkar, A.; Evans, D.; Inglesby, P.; et al. Factors associated with COVID-19-related death using OpenSAFELY. Nature 2020, 584, 430-436. [CrossRef] [PubMed]

19. Thakur, B.; Dubey, P.; Benitez, J.; Torres, J.P.; Reddy, S.; Shokar, N.; Aung, K.; Mukherjee, D.; Dwivedi, A.K. A systematic review and meta-analysis of geographic differences in comorbidities and associated severity and mortality among individuals with COVID-19. Sci. Rep. 2021, 11, 8562. [CrossRef]

20. Wu, Z.; McGoogan, J.M. Characteristics of and Important Lessons From the Coronavirus Disease 2019 (COVID-19) Outbreak in China: Summary of a Report of 72314 Cases From the Chinese Center for Disease Control and Prevention. JAMA 2020, 323, 1239-1242. [CrossRef] [PubMed]

21. Jager, K.J.; Kramer, A.; Chesnaye, N.C.; Couchoud, C.; Sánchez-Álvarez, J.E.; Garneata, L.; Collart, F.; Hemmelder, M.H.; Ambühl, P.; Kerschbaum, J.; et al. Results from the ERA-EDTA Registry indicate a high mortality due to COVID-19 in dialysis patients and kidney transplant recipients across Europe. Kidney Int. 2020, 98, 1540-1548. [CrossRef] [PubMed]

22. Steil, H.; Amato, C.; Carioni, C.; Kirchgessner, J.; Marcelli, D.; Mitteregger, A.; Moscardo, V.; Orlandini, G.; Gatti, E. EuCliD ${ }^{\circledR}$-A Medical Registry. Methods Inf. Med. 2004, 43, 83-88. [PubMed]

23. Merello Godino, J.I.; Rentero, R.; Orlandini, G.; Marcelli, D.; Ronco, C. Results from EuCliD®(European Clinical Dialysis Database): Impact of shifting treatment modality. Int. J. Artif. Organs 2002, 25, 1049-1060. [CrossRef]

24. European Commission Joint Research Centre-ISPRA-Space, Security and Migration Directorate (JRC). Available online: https: / / covid-statistics.jrc.ec.europa.eu/ (accessed on 12 July 2020).

25. Chen, T.; Guestrin, C. XGBoost: A Scalable Tree Boosting System. In Proceedings of the 22nd ACM SIGKDD International Conference on Knowledge Discovery and Data Mining, San Francisco, CA, USA, 13-17 August 2016.

26. Available online: https://github.com/dmlc/xgboost (accessed on 21 December 2019).

27. Van Rossum, G. Python Tutorial; CreateSpace Independent Publishing Platform; (online publisher); 1995.

28. Ling, C.X.; Huang, J.; Zhang, H. AUC: A better measure than accuracy in comparing learning algorithms. In Advances in Artificial Intelligence. Canadian AI 2003; Lecture Notes in Computer Science (Lecture Notes in Artificial Intelligence); Springer: Berlin/Heidelberg, Germany, 2003; Volume 2671, pp. 329-341.

29. Lundberg, S.M.; Lee, S.-I. Unified Approach to Interpreting Model Predictions. In Proceedings of the 31st Conference on Neural Information Processing Systems (NIPS 2017), Long Beach, CA, USA, 4-9 December 2017; 2017.

30. Abbas, M.; Robalo Nunes, T.; Martischang, R.; Zingg, W.; Iten, A.; Pittet, D.; Harbarth, S. Nosocomial transmission and outbreaks of coronavirus disease 2019: The need to protect both patients and healthcare workers. Antimicrob. Resist. Infect. Control 2021, 10, 7. [CrossRef]

31. Leeds, C. COVID 19: Health care workers, risks, protection and transmission. Lancet Reg. Health 2021, 1, 100022. [CrossRef]

32. La Milia, V.; Bacchini, G.; Bigi, M.C.; Casartelli, D.; Cavalli, A.; Corti, M.; Crepaldi, M.; Limardo, M.; Longhi, S.; Manzoni, C.; et al. COVID-19 Outbreak in a Large Hemodialysis Center in Lombardy, Italy. Kidney Int. Rep. 2020, 5, 1095-1099. [CrossRef]

33. Kliger, A.S.; Silberzweig, J. Mitigating risk of COVID-19 in dialysis facilities. Clin. J. Am. Soc. Nephrol. 2020, 15, 707-709. [CrossRef] [PubMed]

34. Basile, C.; Combe, C.; Pizzarelli, F.; Covic, A.; Davenport, A.; Kanbay, M.; Kirmizis, D.; Schneditz, D.; Van Der Sande, F.; Mitra, S. Recommendations for the prevention, mitigation and containment of the emerging SARS-CoV-2 (COVID-19) pandemic in haemodialysis centres. Nephrol. Dial. Transplant. 2020, 35, 737-741. [CrossRef]

35. Kliger, A.S.; Cozzolino, M.; Jha, V.; Harbert, G.; Ikizler, T.A. Managing the COVID-19 pandemic: International comparisons in dialysis patients. Kidney Int. 2020, 98, 12-16. [CrossRef]

36. Marcelli, D. EuCliD (European Clinical Database): A database comparing different realities. J. Nephrol. 2001, 14, S94-S100.

37. Richards, N.; Ayala, J.A.; Cesare, S.; Chazot, C.; Di Benedetto, A.; Gassia, J.P.; Merello, J.I.; Rentero, R.; Scatizzi, L.; Marcelli, D. Assessment of quality guidelines implementation using a continuous quality improvement programme. Blood Purif. 2007, 25, 221-228. [CrossRef]

38. Marcelli, D.; Moscardó, V.; Steil, H.; Day, M.; Kirchgessner, J.; Mitteregger, A.; Orlandini, G.; Gatti, E. Data management and quality assurance for dialysis network. Contrib. Nephrol. 2002, 137, 293-299. [CrossRef]

39. Delamater, P.L.; Street, E.J.; Leslie, T.F.; Yang, Y.T.; Jacobsen, K.H. Complexity of the basic reproduction number (R0). Emerg. Infect. Dis. 2019, 25, 1-4. [CrossRef]

40. Corbett, R.W.; Blakey, S.; Nitsch, D.; Loucaidou, M.; McLean, A.; Duncan, N.; Ashby, D.R.; Appelbe, M.; Brown, E.; Cairns, T.; et al. Epidemiology of COVID-19 in an urban dialysis center. J. Am. Soc. Nephrol. 2020, 31, 1815-1823. [CrossRef]

41. Meyers, L.A.; Pourbohloul, B.; Newman, M.E.J.; Skowronski, D.M.; Brunham, R.C. Network theory and SARS: Predicting outbreak diversity. J. Theor. Biol. 2005, 232, 71-81. [CrossRef] 
42. Frieden, T.R.; Lee, C.T. Identifying and interrupting superspreading events-implications for control of severe acute respiratory syndrome coronavirus 2. Emerg. Infect. Dis. 2020, 26, 1061-1066. [CrossRef] [PubMed]

43. Herrera, J.L.; Srinivasan, R.; Brownstein, J.S.; Galvani, A.P.; Meyers, L.A. Disease Surveillance on Complex Social Networks. PLoS Comput. Biol. 2016, 12, e1004928. [CrossRef] [PubMed]

44. Zwald, M.L.; Lin, W.; Sondermeyer Cooksey, G.L.; Weiss, C.; Suarez, A.; Fischer, M.; Bonin, B.J.; Jain, S.; Langley, G.E.; Park, B.J.; et al. Rapid Sentinel Surveillance for COVID-19-Santa Clara County, California, March 2020. Morb. Mortal. Wkly. Rep. 2020, 69, 419-421. [CrossRef]

45. Colman, E.; Holme, P.; Sayama, H.; Gershenson, C. Efficient sentinel surveillance strategies for preventing epidemics on networks. PLoS Comput. Biol. 2019, 15, e1007517. [CrossRef]

46. Monaghan, C.; Larkin, J.; Chaudhuri, S.; Han, H.; Jiao, Y.; Bermudez, K.; Weinhandl, E.; Dahne-Steuber, I.; Belmonte, K.; Neri, L.; et al. Artificial Intelligence for COVID-19 Risk Classification in Kidney Disease: Can Technology Unmask an Unseen Disease? medRxiv 2020. [CrossRef] 